\title{
Development of the pig placenta*
}

\author{
J.L. Vallet, J.R. Miles and B.A. Freking \\ USDA, ARS, U.S. Meat Animal Research Center, \\ P. O. Box 166, State Spur 18D, Clay Center, Nebraska 68933, USA
}

\begin{abstract}
Placental insufficiency results in fetal loss, low birth weight, stillbirth, preweaning mortality and poor growth. Placental development begins at conceptus elongation, which is a primary factor controlling the size of the placenta. After elongation, the allantois develops outward from the embryo to establish the allantochorion, which defines the size of the functional placenta. During implantation, chorionic trophoblasts adhere to endometrial epithelial cells. Placental structures known as areolae develop at the openings of the endometrial glands and take up endometrial gland secreted products (histotrophe). Between day 30 and 35 of gestation, the adhered trophoblast-endometrial epithelial bilayer undergoes microscopic folding. Fetal and maternal capillaries develop adjacent to the bilayer and blood flows are arranged in a cross-countercurrent manner. Except for nutrients secreted by the glands, nutrient exchange takes place between these capillaries within these folds. By day 85 , the folds deepen and become more complex, increasing surface area. The epithelial bilayer thins and capillaries indent the plane of each layer (but do not penetrate), reducing distance between capiliaries. The folded bilayer is surrounded by endometrial stroma on the maternal side and placental stroma on the fetal side. The fetal-placental stroma is partially composed of glycosaminoglycans, the most abundant being hyaluronan and heparan sulfate. Changes in both hyaluronoglucosaminidase and heparanase during placental development suggest that these enzymes play a role in placental development. In addition to structural modifications, various nutrient specific transport mechanisms exist. These mechanisms are likely to be as important to transport of specific nutrients as placental size or structure.
\end{abstract}

\section{Introduction}

The number of piglets weaned per sow on a yearly basis is a useful measure of sow productivity in breeding herds. The number of fully formed piglets and the stillbirth and preweaning mortality rates influence the number of piglets weaned. Placental function influences each of these components. At its worst, placental insufficiency results in fetal loss during pregnancy. However, even when placental insufficiency is not severe enough to cause death of the fetus, it still reduces piglet birth weights, which is strongly associated with both stillbirth

E-mail: jeff.vallet@ars.usda.gov

* Mention of trade names or commercial products in this paper is solely for the purpose of providing specific information and does not imply recommendation or endorsement by the U.S. Department of Agriculture. 
rate (Tuchscherer et al. 2000) and preweaning mortality (Lay et al. 2002). In addition, most preweaning mortality occurs within 2 days of birth (England 1974), supporting the concept that poor fetal development is the root cause of most preweaning mortality. If piglets survive, their growth rates are permanently impaired (Tilley et al. 2007).

The weights of the fetus and the fetal components of the placenta (allanto- and amniochorion, hereby called "fetal-placenta") can vary widely even within the same litter, and are correlated when fetal-placental weight decreases below a threshold weight (Vallet 2000). This clearly indicates that fetal-placental weight is a primary factor contributing to the generation of runt piglets. The residual variance of fetal weights after fitting the effect of fetal-placental weight partially represents the effect of other characteristics of the placenta that determine its function (i.e., surface area, structure, vascularity). Because of the poor performance of low birth weight piglets, the goal of the swine producer is for every sow to give birth to a large litter of large, uniformly developed piglets. Because the weight of the piglet is correlated with the weight and function of the fetal-placenta, meeting this goal requires that we understand how the fetal placenta develops in terms of both its final weight and its functionality.

\section{Fetal-placental weight and fetal weight}

The relationship between fetal-placental weight and fetal weight is curvilinear (Vallet 2000), indicating that beyond a certain size fetal placenta, the fetal-placental weight ceases to influence fetal weight. Thus, fetal-placental weight is relevant primarily to underweight fetuses. Within the fetal-placental weight range that affects fetal weight, differences in fetal-placental weight do not result in fully proportional changes in fetal weight. This can be demonstrated using the relative growth rate equation of Huxley (1932) to examine relationships between fetalplacental and fetal weights. Using the data reported in Freking et al. (2007), the slopes of the relationships between log fetal-placental weights and log fetal weights were 0.20 on day 25 , 0.26 on day $45,0.44$ on day $65,0.57$ on day 85 , and 0.69 on day 105 . A slope of 1 indicates fully proportional growth relationships. Because these slopes are uniformly less than 1 , they indicate that compensatory mechanisms exist during gestation to minimize decreases in fetal weight when fetal-placental weight is decreased (i.e., a fetal sparing effect). They also indicate that these mechanisms become progressively less effective with advancing gestation. These compensatory mechanisms need not be confined to the fetal placenta, mechanisms within the uterus or the fetus could also compensate for reduced fetal-placental weight.

\section{Relationship between conceptus elongation and fetal-placental size}

It is well established that swine conceptuses undergo elongation at about the time of maternal recognition of pregnancy (Perry \& Rowlands 1962, Geisert et al. 1982), reaching lengths $\sim 1$ $\mathrm{m}$, but occupying $\sim 30 \mathrm{~cm}$ of uterine space due to extensive folding of the endometrial lining. Elongation of the conceptus likely is a primary determinant of the amount of uterine space and maternal resources available to each developing conceptus. It also appears that most pig blastocysts cease elongation when they come into proximity with another conceptus, because individual conceptuses typically do not overlap with each other within the uterus until later in gestation (Perry \& Rowlands, 1962, Ashworth et al. 1998), although exceptions to this have been noted (Crombie 1972, Bjerre et al. 2008) and this mechanism can clearly be exceeded. The initiation of elongation of blastocysts within a litter is relatively synchronous. However, a small subset of blastocysts often do not elongate with the majority of littermates. Experiments in which conceptuses were recovered just after initiation of elongation report obtaining elongated 
blastocysts along with a minority population of blastocysts that remain spherical (Geisert et al. 1982, Pope et al. 1988). The mechanism that initiates elongation is not known. It has been suggested that the diversity in initiation of elongation may be explained by differences in the timing of ovulation of individual ova (Pope et al. 1988). However, later work using ultrasound measurement of ovulation suggests that the difference in time of ovulation from the first to last ovum does not explain the differences in elongation initiation (Soede et al.1992). On the other hand, it is not clear whether ova that are late to ovulate are as developmentally competent as those that ovulate earlier. Thus, although the timing of ovulation may not explain the diversity in conceptus elongation, differences in developmental competence between earlier and later ovulating ova may play a role in conceptus diversity during elongation (Xie et al. 1990).

Once initiated, elongation of the pig blastocyst occurs very rapidly, and the rate has been estimated to be $\sim 45 \mathrm{~mm} / \mathrm{h}$ (Geisert et al. 1982). Because this estimate was made by comparing the elongation of different blastocysts at two different times, this rate is approximate. It seems likely that elongation rate could vary between individual blastocysts, and that this variation contributes to variation in elongation success. However, methods are lacking to assess individual conceptus variation in elongation rate because once removed from the uterus for observation, the process of elongation is interrupted.

Another aspect of elongation that affects conceptus length is its spontaneous termination. The effect of this is clearly evident in Meishan pigs. Meishan conceptuses are smaller at all stages of development and terminate elongation at smaller placentas, resulting in smaller placenta (Ford 1997). This potentially limits individual conceptus interaction within the uterus, improving the outcome of elongation for that portion of the litter experiencing delays. Curiously, this would result in better uniformity of conceptus size after elongation has occurred, which has been reported in Meishans (Bazer et al. 1988). The reduction in conceptus size in Meishans is associated with reductions in uterine protein secretion during early pregnancy (Vallet et al. 1998a). Interestingly, treatment of Meishan pigs during early pregnancy with estrogen, which stimulates uterine protein secretion, increased placental size (Wilson \& Ford 1999), but estrogen had no effect on placental size in European breed pigs (Vallet \& Christenson 2004). This is also consistent with a lack of effect of treatment of gilts with estrogen on day 9 and 10 of gestation on elongation (Blair et al. 1991), although this treatment does result in complete embryo loss within a few days after elongation, possibly due to changes in the luminal endometrial epithelial cell glycocalyx.

Thus, the size of the uterus, the number of conceptuses, the relative timing of initiation of elongation, the relative speed of elongation, and the length of termination of elongation all interact to determine the ultimate sizes of each resulting placenta in the litter. Ideally, uniform initiation and speed of elongation would result in the uniform division of the available maternal resources among the members of any size litter. However, in the extreme, this could lead to uniform failure of all conceptuses in the litter if the division of the uterine space was such that no conceptus received an adequate amount. The diversity that occurs in elongation may provide a mechanism whereby some successful pregnancies occur even in this case.

\section{Fetal-placental growth after elongation}

A logical question to ask is whether the eventual size of the fetal placenta is fixed at elongation. The fetal placenta continues to grow in weight until day 60 to 70 of gestation, after which its growth rate decreases (Freking et al. 2007). Vonnahme et al. (2000) reported that crushing every other fetus on day 40 of gestation increased fetal-placental weights of the remaining conceptuses on day 112 of gestation, but did not affect fetal weights. In our own recent experiment (Vallet 
et al. 2009), fetuses at the ovarian or cervical ends of the uterine horns were crushed on day 35 of pregnancy and adjacent fetal placenta and fetuses were compared to nonadjacent fetal placenta and fetuses on day 105. Results indicated that both the fetal placenta and fetuses were heavier adjacent to a crushed fetus, but the increase was only about $10 \%$. In addition, fetal placentas were asymmetrical, the side of the fetal placenta adjacent to the crushed fetus was longer from umbilical junction to tip compared to the nonadjacent side. These results clearly demonstrate that (1) most of the eventual weight of the fetal-placenta is established before day 35 of pregnancy, and (2) there is a limited ability of conceptuses to benefit from the demise of an adjacent conceptus if it occurs between day 35 to 40 of gestation.

\section{Fetal-placental structure related to function}

There is clearly more to placental development than changes in size during gestation. The conceptus begins to attach to the endometrium beginning around day 13 (Keys et al. 1986, Stroband \& Van der Lende 1990) with formal implantation occurring around day 18 (BielanskaOsuchowska 1979). The first placental structure that develops is the yolk sac placenta, which then regresses. This is followed by the development of the allantois, which migrates into the elongated chorion. That portion of the chorion where the allantois does not reach becomes the "necrotic tip". The portion of the chorion that fuses with the allantois becomes vascularized and is the functional fetal placenta (Friess et al. 1980). Very little is known about factors controlling the migration of the allantois outward into the chorion, including why it stops. The chorioallantois then fills with allantoic fluid, which presses the chorioallantois against the walls of the uterus. This most likely aids in the process of implantation and also provides a mechanical stimulus for growth (Vogel \& Sheetz 2006) of both the uterus and the fetal placenta until the fluid peaks around day 30 of gestation, after which the volume of allantoic fluid recedes to day 45 (Knight et al. 1977). Fluid volumes again increase to peak at day 60 and recede again until the volume is relatively minimal by the end of gestation. At the mouths of the uterine glands, the placental areolae develop beginning about day 15 of gestation (Bielanska-Osuchowska 1979, Leiser \& Dantzer 1994), and are specialized regions of the trophoblast epithelium that take up secreted products from the uterine glands. Elsewhere on the surface of the chorioallantois, the attached trophoblast-endometrial epithelial bilayer develops microscopic folds beginning $\sim$ day 35 of gestation (MacDonald 1976, Dantzer 1984). Using microcorrosion casts, Leiser \& Dantzer (1988) reported that the maternal and fetal capillaries are arranged in net-like structures on the maternal and fetal sides, respectively, of the folded bilayer and that they are arranged in a cross-countercurrent fashion. Maternal blood enters the folded structure near the top of the folds and leaves from the bottom. Fetal blood enters the folded structure near the bottom and leaves from the top. Thus, maternal-fetal exchange takes place within the folded bilayer, because this is the area of closest contact between the maternal and fetal capillaries.

Maternal-fetal exchange given this arrangement is maximized by increased folded bilayer surface area, increased capillary density on either side of the folded epithelial bilayer, and reduction in the distance between the capillaries. During later gestation, secondary folds in the epithelial bilayer develop, increasing the maternal-fetal interaction surface area (Friess et al. 1980). In addition, a recent study in our laboratory (Vallet \& Freking 2007) indicated that the depths of the folds increased during later gestation, accounting for much of the increase in surface area, and is greater in the fetal placentas of small fetuses, suggesting a possible compensatory mechanism for small placental size/lack of uterine space.

In regards to capillary density, microcasting of the fetal capillaries indicates that their density increases with advancing gestation (see plates 4 and 5 of MacDonald 1976). A visual appraisal of 
these images suggests that little room for improvement in capillary density during late gestation may be possible. Nevertheless, other reports indicate that placental vascularity is greater in Meishan fetal placentas compared to Yorkshire placentas (Wilson et al. 1998) although it is not clear from this report whether the vascularity measured was only those capillaries adjacent to the folded bilayer.

Regarding the distance between capillaries, it has been reported that the capillaries adjacent to the folded bilayer become indented within the planes of both the maternal and trophoblast epithelial layer during late gestation, although both epithelial layers remain intact even during late gestation (Friess et al. 1980). This report indicated that the intercapillary distance is as little as $2 \mu \mathrm{m}$. Thus, it appears that all of the functionally relevant physical characteristics of the pig fetal placenta improve with advancing gestation.

At the same time that the folded bilayer widens, the thickness of the fetal-placental stroma outside the folds decreases (Vallet \& Freking 2007). In the fetal placenta of the smallest fetuses within a litter, the average thickness of the fetal-placental stroma outside the folds is reduced at all stages of gestation compared to larger littermates and, in some cases, there is no remaining fetal-placental stroma outside the folded bilayer. We have suggested that the fetal-placental stroma external to the folded bilayer represents room for further deepening of the placental folds to further increase bilayer surface area. A consequence of this hypothesis is that in fetal placenta of small fetuses where no additional fetal-placental stromal area exists external to the folds, no further widening of the folds may be possible. This provides a possible explanation for intrauterine crowding induced fetal losses that occur during late gestation (Freking et al. 2007).

These ideas suggest that fold development may be a primary contributor to placental efficiency, making an understanding of fold development key to improvements in pig placental function. Interestingly, the gross morphology of the trophoblast epithelial cells within the folded bilayer of the placenta is not uniform. In this review, all references to direction and position of cell types will be after orienting sections with the fetal placenta toward the top of the image, and the maternal placenta (i.e., endometrium) toward the bottom. In this orientation, trophoblast cells at the top of the folds of the bilayer are tall columnar. Along the sides and at the bottom of the folds, trophoblast epithelial cells are cuboidal (Friess et al. 1980). This difference in morphology suggests differences in function, but these differences have not been explored. Friess et al. (1980) suggested that the tall columnar cells at the tops of the folds are involved in macromolecular transport due to their secretory appearance. Electron microscope studies by Dantzer et al. (1981) support this possibility, but there is no other evidence to support this suggestion. Our investigation of expression of membrane-bound folate binding protein (Kim \& Vallet 2007) suggests relatively uniform expression of this gene in both cell types. A detailed exploration of gene expression and protein production by these cell types is needed to resolve differences in function between these cells. However, their position at the tops of the folds, nearest to the thinning fetal-placental stroma, suggests that these cells may play a central role in fold development. Also interesting is the proximity of these cells to incoming maternal blood given the structure of the vasculature reported by Leiser \& Dantzer (1988). Do the columnar cells at the tops of the folds develop in response to the nutrient rich environment provided by preexisting or developing maternal blood vessels, or do the columnar cells induce the underlying maternal vasculature? This is a key question, because it will determine whether strategies should focus on placental vascular development or generation of tall columnar trophoblast epithelial cells.

We hypothesized that generation of the folded structure at a minimum requires modification of the fetal-placental stroma. How this is accomplished depends on its composition. Stromal extracellular matrix is composed of various proteins and glycosaminoglycans (GAG), and a previous study of fetal-placental GAG content indicated that the most abundant GAG were 
hyaluronan and heparan sulfate (Steele \& Froseth 1980). We confirmed and extended these observations by measuring hyaluronan in fetal-placental tissues from day 25 to 105 of gestation and localizing hyaluronan in fetal-placental tissues. Hyaluronan content of fetal-placental tissue is low on day 25 of gestation, increases dramatically by day 45, and remains high to day 105 . Hyaluronan content increases further from day 85 to 105 of gestation in placenta of small fetuses. Localization indicated that hyaluronan was a component of the entire fetal-placental stromal tissue (Vallet \& Freking 2006).

Given that hyaluronan is a component of the fetal-placental stroma, we hypothesized a role for hyaluronoglucosaminidase (HYAL) in the changes in the fetal-placental stroma that would be necessary for bilayer folding (Vallet et al. 2008). Specific primers were developed to amplify several known HYAL (Csoka et al. 2001) and we were successful in cloning two CDNA corresponding to pig HYAL 1 and one cDNA corresponding to HYAL 2. One of the HYAL 1 CDNAs and the HYAL 2 CDNA obtained were similar to previously described forms of HYAL 1 (Frost et al. 1997) and HYAL 2 (Lepperdinger et al. 1998). The other HYAL 1 CDNA appeared to be a novel truncated form. The truncated region is reported to contain an EGF-like domain (Chao et al. 2007). The consequences of this truncation in terms of function of the resulting proteins require further investigation.

Expression of each form of HYAL mRNA was examined using RT-PCR (Vallet et al. 2008). The full length form of HYAL 1 was similar across gestation. The truncated form of HYAL 1 increased with advancing gestation. The HYAL 2 mRNA decreased with advancing gestation. For all forms examined, expression was greater in the fetal-placental tissue of small fetuses compared to larger fetuses. We also used hyaluronan zymography (Miura et al. 1995) to measure hyaluronoglucosaminidase activity in placental homogenates. Two molecular weight forms were observed, one similar to those previously reported and a second, more abundant, lower molecular weight form. Both molecular weight forms of hyaluronoglucuronidase activity increased with advancing gestation and were greater in the fetal-placental tissue of small fetuses. These results are consistent with a role for hyaluronan metabolism by Hyal 1 and 2 in the development of the pig fetal placenta during gestation.

Heparan sulfate was another abundant GAG present in fetal-placental tissue (Steele \& Froseth 1980). In humans, only a single functional heparanase gene exists, located on human chromosome 4 (McKenzie 2007). Human chromosome 4 is homologous to swine chromosome 8 (Rohrer 1999) in a region where a QTL for litter size is located (King et al. 2003). Heparan sulfates are components of proteins that make up epithelial cell basement membranes (Lopes et al. 2006), and we hypothesized that modifications to the structure of the epithelial bilayer would require heparanase activity because the basement membranes would be altered as part of this process (Miles et al. 2008). Amplification of fetal-placental total RNA using primers specific for heparanase resulted in three cDNAs related to heparanase. One of these forms corresponded to the previously described active form of heparanase (Toyoshima \& Nakajima 1999), the other two coded for truncated forms. Both truncated forms are likely to be enzymatically inactive, and their role in the fetal placenta will require further experimentation. Analysis of fetal-placental total mRNA for the putative active form of heparanase indicated that expression was relatively high on day 25, was less on days 45 and 65 , and increased again on days 85 through 105 of gestation (Miles et al. 2008). In situ hybridization localized heparanase mRNA to the cuboidal trophoblast epithelium lining the sides and bottom of the placental folds (JR Miles, unpublished observations). A closer examination of the folds indicates that the interiors of the folds are also undergoing morphological changes with the area of fetal-placental stroma within the folds becoming more extensive. Thus, it seems likely that heparanase plays a role in these changes, as well as possibly being involved in the indentation of capillaries into the plane of the epithelial bilayer that results in reductions in the maternal-fetal intercapillary distance. 


\section{Placental angiogenesis}

It is obvious that extensive angiogenesis must take place on the fetal and maternal sides of the pig placenta. One of the reasons we chose to study placental hyaluronan and heparan sulfate metabolism is that fragments of both are known to be angiogenic (West et al. 1985, Jakobsson et al. 2006). Thus, expression of these genes could couple changes in fold morphology with capillary development surrounding the bilayer. There is a constellation of other genes reported to participate in one or more aspects of angiogenesis in a variety of tissues (Liekens et al. 2001, Bouis et al. 2006, Lamalice et al. 2007, Otrock et al. 2007, Ribatti et al. 2007). These include fibroblast growth factors (FGF; Presta et al. 2005), vascular endothelial growth factors (VEGF; Dai \& Rabie 2007), transforming growth factors (TGF; Lebrin et al. 2005), and the angiopoietins (Fiedler \& Augustin 2006). In addition, numerous other genes and metabolites interact with these known angiogenic factors and modulate their activity. Focusing on hyaluronan and hyaluronoglucuronidases, several proteins are known to bind hyaluronan including CD44 (Knudson et al. 2002), receptor for hyaluronan mediated motility (RHAMM; Savani et al. 2001), and other hyaladherens (Turley et al. 2002). Numerous proteins inhibit hyaluronoglucuronidase activity (Mio \& Stern 2002). Turning to heparanase, activity requires proteolytic cleavage (Shafat et al. 2006). Heparan sulfate is involved in receptor binding for both basic FGF (Schlessinger et al. 2000) and VEGF (Jakobsson et al. 2006), partially explaining its role in angiogenesis. The presence of VEGF (Winther et al. 1999) and TGF $\beta$ (Gupta et al. 1998) in the pig placenta have been reported. Placental VEGF expression is correlated with vascularity of the placenta during gestation (Vonnahme \& Ford 2004). Given the complexity of these interacting systems, we have just scratched the surface of regulation of placental angiogenesis in the pig.

\section{Nutrient specific transport mechanisms}

Because the pig placenta is epitheliochorial, nutrients must pass through either two sets of epithelial cell tight junctions or four sets of cell membranes and two epithelial cell cytoplasms to get from the maternal blood supply to the fetal blood supply. The cytoplasmic distance is greatly reduced during late gestation (Friess et al. 1980). Tight junctions are selective barriers to the passage of solutes, thus passage depends on their permeability for different solutes (Schneeberger \& Lynch 2004). The phospholipid bilayer composition of cell membranes means that each membrane is a hydrophobic barrier, which prevents passage of polar molecules like sugar. One way this is dealt with is by incorporating transport proteins in the membrane to allow passage of molecules that are incompatible with the lipid environment of the plasma membranes. Generally, membrane passage can take place with (active transport) or without (facilitated diffusion) expending cellular energy. Another way to accomplish passage is through incorporation of the solute into endometrial epithelial protein, which is then secreted. This requires uptake by the fetal-placental epithelium and transport across the cell, to be released to the fetal blood stream. The following describes some of the known mechanisms facilitating transport of oxygen, glucose, amino acids, lipids and vitamins and minerals.

\section{Oxygen}

Molecular oxygen is small and nonpolar and readily diffuses. Nevertheless, the low oxygen affinity of maternal hemoglobin and the higher oxygen affinity of fetal hemoglobin facilitates the transfer of oxygen from mother to fetus (Comline \& Silver 1974). In the pig fetus, embryonic hemoglobin production gives way to adult hemoglobin around day 30 of gestation, the pig does 
not produce a fetal hemoglobin similar to that of humans (Weber et al. 1987). Nevertheless, the hemoglobin present in fetal red blood cells has a higher affinity for oxygen compared to maternal hemoglobin (Zhang et al. 2006). The difference in oxygen affinity is the result of differences in 2,3-diphosphoglycerate concentrations in maternal and fetal red blood cells (Sasaki \& Chiba 1983). Increased concentration of 2,3-diphosphoglycerate reduces hemoglobin oxygen affinity (Kim \& Duhm 1974). Concentrations of 2,3-diphosphoglycerate remain low throughout fetal life in the pig and rapidly increase after birth (Gluszak 1979). A single enzyme, 2,3 bisphosphoglycerate synthase/phosphatase, catalyzes the synthesis and degradation of 2,3-diphosphoglycerate in red blood cells (Mulquiney et al. 1999). The factors controlling the activity of this enzyme during fetal life and the mechanism of the dramatic increase in 2,3diphosphoglycerate levels after birth are not known.

\section{Clucose}

Glucose and other monosaccharides are polar compounds that do not diffuse readily through lipid bilayer membranes. Two groups of glucose transporter genes exist to overcome this problem, sodium-dependent glucose transporters (gene SLC5A, protein SGLT) and facilitative glucose transporters (gene SLC2A, protein GLUT; Zhao \& Keating 2007). The SGLT proteins transport glucose from low to high concentrations through the coupling of glucose with sodium transport from high to low sodium concentrations. The sodium is subsequently pumped from the cell by $\mathrm{Na} / \mathrm{K} / \mathrm{ATP}$ ase, thus glucose transport by this mechanism expends cell energy. The GLUT proteins are bidirectional transport proteins that transfer solute from high to low concentration and do not expend cell energy. There appears to be no report of the investigation of either of these gene classes in the swine placenta. Nevertheless, fetal blood glucose concentrations are considerably lower than maternal blood glucose concentrations (Pere 1995, Fowden et al. 1997), indicating that glucose transport occurs down a concentration gradient and pointing to GLUT protein mediation of glucose transfer. Examination of the swine gene index (http://compbio.dfci. harvard.edu/tgi/cgi-bin/tgi/gimain.pl?gudb = pig) indicates that expressed sequence tags (EST) corresponding to sodium-glucose cotransporter 10 (SGLT5) and facilitative glucose transporters 1 (GLUT1), 2 (GLUT2), and 3 (GLUT3) have been isolated from placenta, and EST corresponding to sodium-glucose cotransporter 3 (SGLT3) and facilitative glucose transporters 1 (GLUT1), 3 (GLUT3) and 5 (GLUT5) have been isolated from uterus. The GLUT1 and 3 proteins transport glucose (Olson \& Pessin 1996); GLUT2 transports glucose and fructose (Colville et al. 1993) but has the highest affinity for glucosamine (Uldry et al. 2002). The GLUT5 transporter is specific for fructose (Zhao \& Keating 2007). Together, glucose transporters present in endometrial and trophoblast epithelial cells allow glucose to cross all four cell membrane barriers.

The pig placenta is fructogenic (Rama et al. 1973), converting a portion of the incoming glucose into fructose, and fetal plasma levels of fructose are actually higher than glucose (4.5 versus $2 \mathrm{mM}$; Pere 1995). It has been suggested that this placental ability sequesters glucose in the fetus because fructose does not escape back into the maternal circulation (Pere 1995). Conversion of glucose to fructose would also serve to maintain lower fetal glucose concentrations, widening the maternal to fetal glucose concentration gradient, and improving glucose transport to the fetus. However, the fetus does not appear to use fructose because umbilical artery and vein fructose concentrations do not differ appreciably (Pere 1995). This calls into question the utility of sequestration of glucose in the form of fructose. However, it appears that the fetal liver is also fructogenic (White et al. 1979). Fetal circulation in the pig is such that all the blood returning from the placenta passes through a structure similar to a ductus venosus, and has relatively intimate contact with fetal liver tissue (Dickson 1956). In addition 
blood returning to the placenta is actually a mixture of blood processed by the fetus and blood returning from the placenta (Kiserud 2005). Thus fructose concentrations in the umbilical artery may not fully reflect fructose metabolism by the fetus. The fructogenic activity of the liver may mask any substantial use of fructose by the fetus because fructose may be replaced as it is metabolized. On the other hand, ${ }^{14} \mathrm{C}$-fructose tracer studies in sheep conceptuses, which are also fructogenic, indicate that the rate of usage of fructose by the sheep conceptus is one-fifth that of glucose (Meznarich et al. 1987).

Two alternative pathways exist to generate fructose from glucose (Rama et al. 1973). The first is the Embden-Meyerhoff-Cori pathway in which glucose is first phosphorylated to glucose6-phosphate by hexokinase, which is then converted to fructose-6-phosphate by isomerase. Alternatively, glucose can be converted to fructose through the sorbitol pathway, involving aldose reductase and ketose (sorbitol) reductase. The latter pathway has the advantage that ATP is not consumed. It has been reported that the pig placenta lacks ketose reductase (Rama et al. 1973), but ESTs for both aldose reductase and sorbitol reductase have been obtained from pig placenta. Thus, it is likely that both pathways exist in the placenta so the primary enzyme pathway controlling conversion of glucose to fructose requires investigation.

Curiously, fructose-6-phosphate participates in a pathway that generates the $\mathrm{N}$-acetylglucosamine needed for hyaluronan and other GAG synthesis (Holden et al. 2003, Moussian 2008). Fructose6-phosphate is converted to glucosamine-6-phosphate in a reaction catalyzed by glutamine fructose-6-phosphate amidotransferase (GFAT). This reaction consumes glutamine, which has the highest concentration of any amino acid in fetal plasma (Wu et al. 1995). Wen et al. (2005) indicated that the GFAT enzyme, through generation of glucosamine from fructose-6-phosphate, activates mammalian target of rapamycin (mTOR), which increases the proliferation of a human trophoblast cell line. In addition, the affinity of CLUT-2 for glucosamine is an order of magnitude higher than for glucose and fructose (Uldry et al. 2002), suggesting that glucosamine concentrations may regulate glucose and fructose transport by this transporter through competition for binding. It seems possible that the pathways that generate glucosamine from fructose, and fructose from glucose, could link GAG synthesis, trophoblast proliferation and glucose transport, and may play a role in changes in placental structure in response to reduced placental size. Clearly, these pathways and their role in placental development require further study.

\section{Amino acids}

Wu et al. (1995) reported the concentrations of amino acids in fetal and maternal circulations. Only the concentrations of cysteine, glycine, histidine, leucine, phenylalanine, and tryptophan were lower in fetal umbilical venous plasma compared to maternal plasma, and total $\alpha$-amino acid concentration was greater in fetal plasma compared to maternal plasma. This suggests that amino acid transport must involve one or more active transport mechanisms. Because of interconversions among amino acids and the fact that some amino acids can be synthesized from other metabolic substrates, concentrations of individual amino acids do not allow firm conclusions on transport mechanisms.

Of the amino acids, glutamine concentrations display the greatest fetal maternal difference, and the placenta is capable of synthesizing glutamine from other amino acids (Self et al. 2004). Arginine concentrations are also unusually high in fetal fluids (Wu et al. 1996). Interestingly, arginine supplementation has been reported to improve litter size (Mateo et al. 2006, Hazeleger et al. 2007) and has been proposed to play a role in numerous functions during pregnancy ( $\mathrm{Wu}$ et al. 2004). These include nitrous oxide (NO) generation, polyamine synthesis and creatine generation (Morris 2007, Brosnan \& Brosnan 2007). While, NO (Wu et al. 1998) and polyamine 
synthesis (Wu et al. 2005) have received some attention, creatine is thought to be responsible for shuttling ATP from the mitochondria to the cytoplasm (Paddon-Jones et al. 2004) and is thus essential for energy utilization in the fetus. Because low birthweight piglets have decreased survival within the first two days of life, the ability to utilize energy efficiently at birth could have a profound effect on piglet survival.

Finch et al. (2004) have investigated leucine uptake by placental trophoblast vesicles. They report that both sodium-dependent and independent mechanisms are present in the pig placenta, and that the sodium-dependent transport capacity of placentas of small fetuses was less than that of larger littermates. Because sodium-dependent transport requires energy to maintain the sodium gradient, this could be an adaptation to decreased availability of energy in small fetuses. Clearly, the mechanisms responsible for amino acid transport and the generation, maintenance, and reasons for the high concentrations of certain amino acids in fetal plasma warrant further investigation.

\section{Lipid transport}

Lipids are higher energy substrates than sugars, thus transport of lipids would be advantageous to the developing pig fetus. Unfortunately, when lipid transport has been measured, it has been found to be low or nonexistent (Thulin et al. 1989, Ramsay et al. 1991). However, Thulin et al. (1989) infused radiolabelled free fatty acids to determine transport by the placenta, which is unlikely to present lipids to the placenta in the same form that lipids typically circulate in the blood. Lipids are typically bound to lipoproteins and are delivered to tissues through receptors for the lipoprotein-lipid complexes (Herrera 2002). Thus, it may be that the capacity of the pig placenta to deliver lipids to the fetus may be underappreciated. In further support of this, certain essential fatty acids do not appear to be synthesized by animal tissues, so some mechanism for delivery of these essential fatty acids must exist (Youdim et al. 2000). Although piglet fat reserves are typically low at birth, one aspect of development that requires lipid is brain myelination (Youdim et al. 2000). Myelin membranes are specialized plasma membrane structures of nerve peripheral cells composed primarily of phospholipid (Deber \& Reynolds 1991). Brain myelination begins before birth in the piglet and likely affects piglet survival after birth (Dickerson et al. 1971). Thus, while the currently available results suggest that lipid transport by the placenta is poor, the opportunity represented by improvements in brain function and piglet survival would seem to be good justification for further exploration of lipid transport by the pig placenta.

\section{Vitamins and minerals}

It is likely that the transport of various vitamins and minerals by the pig placenta differs with each individual nutrient. However, some general concepts can be inferred from the vitamins and minerals for which the transport mechanisms have been explored. Iron is transported to the pig fetus as a component of uteroferrin (Roberts \& Bazer 1988). Pig endometrial glands secrete copious quantities ( $2 \mathrm{~g}$ per day) of uteroferrin (Buhi et al. 1982), which is picked up by fluid phase pinocytosis by the areolae (Raub et al. 1985). Substantial amounts of the iron in uteroferrin are metabolized by the placenta because circulating concentrations of acid phosphatase activity are quite low in fetal plasma (Vallet et al. 1996). However, the fetal liver is also capable of binding uteroferrin by mannose-6-phosphate receptors (Saunders et al. 1985). Finally, circulating plasma uteroferrin can also be cleared by the fetal kidney into the allantois where substantial amounts of uteroferrin are present (Baumbach et al. 1986). A mechanism 
exists in the allantoic fluid to transfer iron from uteroferrin to transferrin, which can then return to the fetus (Buhi et al. 1982). The handling of uteroferrin by the pig conceptus in this way may prevent the oxidizing activity of reduced uteroferrin (Vallet 1995). Thus, iron transport via uteroferrin as a model suggests that the endometrial glands and areolae participate in the delivery of nutrients to the developing pig conceptus, and that the allantoic sac may serve as a storage and protective chamber for metabolites.

Retinol is delivered to the developing pig conceptus bound to retinol binding protein (Clawitter et al. 1990). Retinol plays a role in cell signaling (Duester 2008) and may also participate in providing antioxidant activity for the developing conceptus (Vallet 1995). It is likely that retinol is delivered to the fetus via the areolae in a manner similar to that of uteroferrin (Dantzer \& Winther 2001).

In contrast to uteroferrin and retinol, folate transport to the developing pig conceptus likely takes place through the concerted activities of secreted and placental membrane-bound forms of folate binding protein (Kim \& Vallet 2004). Uterine flushings on days 13 and 15 of the cycle or pregnancy contain large amounts of secreted folate binding protein (Vallet et al. 1998b). Immunohistochemical localization of the secreted form of folate binding protein indicated that it was present in endometrial glands beginning about day 13 of pregnancy until day 20 and disappears by day 35 of pregnancy (Kim \& Vallet 2004). Endometrial mRNA levels for this protein do not follow this pattern (Vallet et al. 1999), and it has not been possible to demonstrate synthesis of secreted folate binding protein by endometrial tissue (J.L. Vallet \& J.G. Kim, unpublished observations). Thus, it seems highly likely that the secreted folate binding protein found in the endometrial glands and in uterine flushings during early pregnancy may originate from serum. The placenta expresses an mRNA for a membrane-bound form of folate binding protein (Vallet et al. 1999), and in situ hybridization indicates that this mRNA is present in trophoblast epithelium of the placental folds (e.g., present in both tall columnar cells and in cuboidal cells) throughout gestation (Kim \& Vallet 2007). Kim \& Vallet (2004) have hypothesized that folate transport is thus accomplished by the sequential effects of secreted folate binding protein during early pregnancy, followed by placental membrane-bound folate binding protein during later gestation. Conceptually, transport with these characteristics is likely to be sensitive during the switchover period (i.e., during early placental development). This period of pregnancy is unusually sensitive to intrauterine crowding (Vonnahme et al. 2002, Freking et al. 2007), and it seems possible that nutrients like folate that transition from histotrophic to placental transport could contribute to the sensitivity of this period.

\section{References}

Ashworth Cl, Ross AW \& Barret P 1998 The use of DNA fingerprinting to assess monozygotic twinning in Meishan and Landrace $x$ Large White pigs. Reproduction Fertility \& Development 10 487-490.

Baumbach GA, Ketcham CM, Richardson DE, Bazer FW \& Roberts RM 1986 Isolation and characterization of a high molecular weight stable pink form of uteroferrin from uterine secretions and allantoic fluid of pigs. The Journal of Biological Chemistry 261 12869-12878.

Bazer FW, Thatcher WW, Martinat-Botte F \& Terqui $M 1988$ Conceptus development in large white and prolific Chinese Meishan pigs. Journal of Reproduction and Fertility $8437-42$.

Bielanska-Osuchowska Z 1979 Ultrastructure of the trophoblast of the pig placenta. Acta Medica Polonica 20 359-360.
Bjerre D, Thorup F, Jorgensen CB, Vejlsted M \& Fredholm M 2008 A study of the occurrence of monochorionic and monozygotic twinning in the pig. Animal Cenetics 40 53-56.

Blair RM, Geisert RD, Zavy MT, Yellin T, Fulton RW \& Short EC 1991 Endometrial surface and secretory alterations associated with embryonic mortality in gilts administered estradiol valerate on days 9 and 10 of gestation. Biology of Reproduction 44 1063-1079.

Bouïs D, Kusumanto Y, Meijer C, Mulder NH \& Hospers GAP 2006 A review on pro- and anti-angiogenic factors as targets of clinical intervention. Pharmacological Research 53 89-103.

Brosnan IT \& Brosnan ME 2007 Creatine: Endogenous metabolite, dietary, and therapeutic supplement. Annual Review of Nutrition 27 241-261. 
Buhi WC, Ducsay CA, Bazer FW \& Roberts RM 1982 Iron transfer between the purple phosphatase uteroferrin and transferrin and its possible role in iron metabolism of the fetal pig. The Journal of Biological Chemistry 257 1712-1723.

Chao KL, Muthukumar L \& Herzberg O 2007 Structure of human hyaluronidase-1, a hyaluronan hydrolyzing enzyme involved in tumor growth and angiogenesis. Biochemistry 46 6911-6920.

Clawitter J, Trout WE, Burke MG, Araghi S \& Roberts RM 1990 A novel family of progesterone-induced, retinolbinding proteins from uterine secretions of the pig. The Journal of Biological Chemistry 265 3248-3255.

Colville CA, Seatter M), Jess TJ, Gould CW \& Thomas HM 1993 Kinetic analysis of the liver-type (GLUT2) and brain-type (GLUT3) glucose transporters in Xenopus oocytes: substrate specificities and effects of transport inhibitors. Biochemical Journal 290 701-706.

Comline RS \& Silver M 1974 A comparative study of blood gas tensions, oxygen affinity and red cell 2,3 DPG concentrations in foetal and maternal blood in the mare, cow and sow. The fournal of Physiology 242 805-826.

Crombie PR 1972 The occurrence of end-to-end fusion between adjacent chorioallantoic sacs in the early pig embryo. Journal of Reproduction and Fertility 29 127-129.

Csoka AB, Frost GI \& Stern R 2001 The six hyaluronidaselike genes in the human and mouse genomes. Matrix Biology 20 499-508.

Dai 1 \& Rabie ABM 2007 VEGF: an essential mediator of both angiogenesis and endochondral ossification. Journal of Dental Research 86 937-950.

Dantzer V 1984 Scanning electron microscopy of exposed surfaces of the porcine placenta. Acta Anatomica 118 96-106.

Dantzer V, Bjorkman N \& Hasselager E 1981 An electron microscopic study of histiotrophe in the interareolar part of the porcine placenta. Placenta 2 19-28.

Dantzer V \& Winther H 2001 Histological and immunohistochemical events during placentation in pigs. Reproduction Supplement 58 209-222.

Deber CM \& Reynolds S] 1991 Central nervous system myelin: structure, function, and pathology. Clinical Biochemistry 24 113-134.

Dickerson JWT, Merat A \& Widdowson EM 1971 Intrauterine growth retardation in the pig. 3 . The chemical structure of the brain. Biology of the Neonate 19 354-362.

Dickson AD 1956 The ductus venosus of the pig. Journal of Anatomy 90 143-152.

Duester G 2008 Retinoic acid synthesis and signaling during early organogenesis. Cell 134 921-931.

England DC 1974 Husbandry components in prenatal and perinatal development in swine. Journal of Animal Science 38 1045-1049.

Fiedler U \& Augustin HG 2006 Angiopoietins: a link between angiogenesis and inflammation. Trends in Immunology 27 552-558.

Finch AM, Yang LG, Nwagwu MO, Page KR, McArdle HJ \& Ashworth CJ 2004 Placental transport of leucine in a porcine model of low birth weight. Reproduction 128 229-235.

Ford SP 1997 Embryonic and fetal development in different genotypes in pigs. Journal of Reproduction and Fertility Supplement 52 165-176.

Fowden AL, Forhead A], Silver M \& MacDonald AA 1997 Glucose, lactate and oxygen metabolism in the fetal pig during late gestation. Experimental Physiology 82 171-182.

Freking BA, Leymaster KA, Vallet JL \& Christenson RK 2007 Number of fetuses and conceptus growth throughout gestation in lines of pigs selected for ovulation rate or uterine capacity. Journal of Animal Science 85 2093-2103.

Friess AE, Sinowatz F, Skolek-Winnisch R \& Träutner W 1980 The placenta of the pig. I. Finestructural changes of the placental barrier during pregnancy. Anatomy and Embryology 158 179-191.

Frost GI, Csóka TB, Wong T \& Stern R 1997 Purification, cloning, and expression of human plasma hyaluronidase. Biochemical and Biophysical Research Communications 236 10-15.

Geisert RD, Brookbank JW, Roberts RM \& Bazer FW 1982 Establishment of pregnancy in the pig: Il. Cellular remodeling of the porcine blastocyst during elongation on day 12 of pregnancy. Biology of Reproduction 27 941-955.

Gluszak A 1979 Effect of 2,3-diphosphoglycerate (2,3-DPG) on haemoglobin affinity to oxygen in fetal and early postnatal period of life in pigs. Acta physiologica Polonica 30 507-515.

Gupta A, Ing NH, Bazer FW, Bustamante LS \& Jaeger LA 1998 Beta transforming growth factors (TGFB) at the porcine conceptus-maternal interface. Part I: Expression of TGFB1, TGFß2, and TGFB3 messenger ribonucleic acids. Biology of Reproduction 59 905-910.

Hazeleger W, Ramaekers P, Smits C \& Kemp B 2007 Effect of Progenos on placenta and fetal development in pigs. Journal of Animal Science 85 (Supplement 2) 98 (Abstract).

Herrera E 2002 Lipid metabolism in pregnancy and its consequences in the fetus and newborn. Endocrine 19 43-55.

Holden HM, Rayment I \& Thoden JB 2003 Structure and function of enzymes of the Leloir pathway for galactose metabolism. The Journal of Biological Chemistry 278 43885-43888.

Huxley IS 1932 Problems in relative growth. The Dial Press, New York, NY.

Jakobsson L, Kreuger J, Holmborn K, Lundin L, Eriksson I, Kjellén L \& Claesson-Welsh L 2006 Heparan sulfate in trans potentiates VEGFR-mediated angiogenesis. Developmental Cell 10 625-634.

Keys JL, King GJ \& Kennedy TG 1986 Increased uterine vascular permeability at the time of embryonic attachment in the pig. Biology of Reproduction 34 405-411.

Kim HD \& Duhm / 1974 Postnatal decrease in the oxygen affinity of pig blood induced by red cell 2,3-DPG. The American lournal of Physiology 226 1001-1006. 
Kim IG \& Vallet IL. 2004 Secreted and placental membrane forms of folate-binding protein occur sequentially during pregnancy in swine. Biology of Reproduction 71 1214-1219.

Kim JG \& Vallet JL. 2007 Placental expression of the membrane form of folate binding protein during pregnancy in swine. Theriogenology 67 1279-1284.

King AH, Jiang Z, Gibson IP, Haley CS \& Archibald AL 2003 Mapping quantitative trait loci affecting female reproductive traits on porcine chromosome 8 . Biology of Reproduction 68 2172-2179.

Kiserud T 2005 Physiology of the fetal circulation. Seminars in Fetal and Neonatal Medicine 10 493-503.

Knight JW, Bazer FW, Thatcher WW, Franke DE \& Wallace HD 1977 Conceptus development in intact and unilaterally hysterectomized-ovariectomized gilts: Interrelations among hormonal status, placental development, fetal fluids and fetal growth. Journal of Animal Science 44 620-637.

Knudson W, Chow G \& Knudson CB 2002 CD44. mediated uptake and degradation of hyaluronan. Matrix Biology 21 15-23.

Lamalice L, Le Bouef F \& Huot I 2007 Endothelial cell migration during angiogenesis. Circulation Research $100782-794$.

Lay DC Ir, Matteri RL, Carroll JA, Fangman TI \& Safranski IJ 2002 Preweaning survival in swine. Journal of Animal Science 80 (E-Supplement 1) E74-E86.

Lebrin F, Deckers $M$, Bertolino P \& Ten Dijke $P$ 2005 TCF- $\beta$ receptor function in the endothelium. Cardiovascular Research 65 599-608.

Leiser R \& Dantzer V 1988 Structural and functional aspects of porcine placental microvasculature. Anatomy and Embryology 177 409-419.

Leiser R \& Dantzer V 1994 Initial vascularization in the pig placenta: II. Demonstration of gland and areolagland subunits by histology and corrosion casts. The Anatomical Record 238 326-334.

Lepperdinger G, Strobl B \& Kreil G 1998 HYAL2, a human gene expressed in many cells, encodes a lysosomal hyaluronidase with a novel type of specificity. The lournal of Biological Chemistry 273 22466-22470.

Liekens S, De Clercq E \& Neyts | 2001 Angiogenesis: regulators and clinical applications. Biochemical Pharmacology 61 253-270.

Lopes CC, Dietrich CP \& Nader HB 2006 Specific structural features of syndecans and heparan sulfate chains are needed for cell signaling. Brazilian lournal of Medical and Biological Research 39 157-167.

MacDonald AA 1976 Uterine vasculature of the pregnant pig: a scanning electron microscope study. The Anatomical Record 184 689-697.

Mateo RD, WU G, Carroll JA, Shinzato I \& Kim SW 2006 Dietary L-arginine supplementation improves pregnancy outcome in gilts. Journal of Animal Science 84 (Supplement2) 49(Abstract).

McKenzie EA 2007 Heparanase: a target for drug discovery in cancer and inflammation. British Journal of Pharmacology 151 1.14.

Meznarich HK, Hay Jr WW, Sparks JW, Meschia G,
Baftaglia FC 1987 Fructose disposal and oxidation rates in the ovine fetus. Quarterly fournal of Experimental Physiology 72 617-625.

Miles J, Vallet J \& Freking B 2008 Molecular cloning and characterization of heparanase mRNA in porcine placenta throughout gestation. Biology of Reproduction 79(Supplement 1) 136 (Abstract).

Mio K \& Stern R 2002 Inhibitors of the hyaluronidases. Matrix Biology 21 31-37.

Miura RO, Yamagata S, Miura Y, Harada T\& Yamagata T 1995 Analysis of glycosaminoglycan-degrading enzymes by substrate gel electrophoresis (zymography). Analytical Biochemistry 225 333-340.

Morris SM Ir 2007 Arginine metabolism: boundaries of our knowledge. The journal of Nutrition 137 1602S-1609.

Moussian B 2008 The role of GICNAC in formation and function of extracellular matrices. Comparative Biochemistry and Physiology Pant B: Biochemistry and Molecular Biology 149 215-226.

Mulquiney PI, Bubb WA \& Kuchel PW 1999 Model of 2,3-bisphosphoglycerate metabolism in the human erythrocyte based on detailed enzyme kinetic equations: in vivo kinetic characterization of 2,3-bisphosphoglycerate synthase/phosphatase using ${ }^{13} \mathrm{C}$ and ${ }^{31} \mathrm{P}$ NMR. Biochemical fournal 342 567-580.

Olson AL \& Pessin JE 1996 Structure, function, and regulation of the mammalian facilitative glucose transporter gene family. Annual Review of Nutrition 16235

Otrock ZK, Mahfouz RAR, Makarem JA \& Shamseddine Al 2007 Understanding the biology of angiogenesis: review of the most important molecular mechanisms. Blood Cells, Molecules and Diseases 39 212-220.

Paddon-Jones D, Borsheim E \& Wolfe RR 2004 Potential ergogenic effects of arginine and creatine supplementation. The fournal of Nutrition $\mathbf{1 3 4}$ 28885-2894S.

Pere MC 1995 Maternal and fetal blood levels of glucose, lactate, fructose, and insulin in the conscious pig. Journal of Animal Science 73 2994-2999.

Perry IS \& Rowlands IW 1962 Early pregnancy in the pig. Journal of Reproduction and Fertility 4 175-188.

Pope WF, Wilde MH \& Xie S 1988 Effecl of electrocautery of nonovulated day 1 follicles on subsequent morphological variation among day 11 porcine embryos. Biology of Reproduction 39 882-887.

Presta M, Dell'Era P, Mitola S, Moroni E, Ronca R \& Rusnati M 2005 Fibroblast growth factor/fibroblast growth factor receptor system in angiogenesis. Cytokine \& Growth Factor Reviews 16 159-178.

Rama F, Castellano MA, Germino NI, Micucci M \& Ohanian C 1973 Histochemical location of ketosereductase in the placenta and fetal tissues. Journal of Anatomy 114 (Pt 1) 109-113.

Ramsay TG, Karousis I, White ME \& Wolverton CK 1991 Fatty acid metabolism by the porcine placenta. Journal of Animal Science 69 3645-3654.

Raub TJ, Bazer FW \& Roberts RM 1985 Localization of the iron transport glycoprotein, uteroferrin, in the porcine 
endometrium and placenta by using immunocolloidal gold. Anatomy and Embryology 171 253-258.

Ribatti D, Conconi MT \& Nussdorfer GG 2007 Nonclassic endogenous novel regulators of angiogenesis. Pharmacological Reviews 59 185-205.

Roberts RM \& Bazer FW 1988 The functions of uterine secretions. Journal of Reproduction and Fertility $\mathbf{8 2}$ 875-892.

Rohrer GA 1999 Mapping four genes from human chromosome 4 to porcine chromosome 8 further develops the comparative map for an economically important chromosome of the swine genome. Animal Cenetics 30 60-62.

Sasaki R \& Chiba H 1983 Role and induction of 2,3-bisphosphoglycerate synthase. Molecular and Cellular Biochemistry 53-54 247-256.

Saunders PTK, Renegar RH, Raub T), Baumbach GA, Atkinson PH, Bazer FW \& Roberts RM 1985 The carbohydrate structure of porcine uteroferrin and the role of the high mannose chains in promoting uptake by the reticuloendothelial cells of the fetal liver. The Journal of Biological Chemistry 260 3658-3665.

Savani RC, Cao G, Pooler PM, Zaman A, Zhou Z \& DeLisser HM 2001 Differential involvement of the hyaluronan (HA) receptors CD44 and receptor for HA-mediated motility in endothelial cell function and angiogenesis. The lournal of Biological Chemistry 276 $36770-36778$.

Schlessinger J, Plotnikov AN, Ibrahimi OA, Eliseenkova AV, Yeh BK, Yayon A, Linhardt RJ \& Mohammadi M 2000 Crystal structure of a ternary FGF-FGFRheparin complex reveals a dual role for heparin in FGFR binding and dimerization. Molecular Cell 6 743-750.

Schneeberger EE \& Lynch RD 2004 The tight junction: a multifunctional complex. American lournal of Physiology. Cell Physiology 286 C1213-C1228.

Self JT, Spencer TE, Johnson CA, Hu J, Bazer FW \& Wu G 2004 Glutamine synthesis in the developing porcine placenta. Biology of Reproduction 70 1444-1451.

Shafat I, Vlodavsky I \& Ilan N 2006 Characterization of mechanisms involved in secretion of active heparanase. The Journal of Biological Chemistry $\mathbf{2 8 1}$ 23804-23811.

Soede NM, Noordhuizen JPTM \& Kemp B 1992 The duration of ovulation in pigs, studied by transrectal ultrasosography, is not related to early embryonic diversity. Theriogenology 38 653-666.

Steele VS \& Froseth JA 1980 Effect of gestational age on the biochemical composition of porcine placental glycosaminoglycans. Proceedings of the Society for Experimental Biology and Medicine $165480-485$.

Stroband HW \& Van der Lende T 1990 Embryonic and uterine development during early pregnancy in pigs. Journal of Reproduction and Fertility Supplement $\mathbf{4 0}$ 261-277.

Thulin AJ, Allee GL, Harmon DL \& Davis DL 1989 Uteroplacental transfer of octanoic, palmitic and linoleic acids during late gestation in gilts. Journal of Animal Science 67 738-745.
Tilley RE, MCNeil CJ, Ashworth CJ, Page KR \& McArdle H) 2007 Altered muscle development and expression of the insulin-like growth factor system in growth retarded fetal pigs. Domestic Animal Endocrinology 32 167-177.

Toyoshima M \& Nakajima M 1999 Human heparanase. Purification, characterization, cloning, and expression. The fournal of Biological Chemistry 274 24153-24160.

Tuchscherer M, Puppe B, Tuchscherer A \& Tiemann U 2000 Early identification of neonates at risk: Traits of newborn piglets with respect to survival. Theriogenology 54 371-388.

Turley EA, Noble PW \& Bourguignon LYW 2002 Signaling properties of hyaluronan receptors. The Journal of Biological Chemistry 277 4589-4592.

Uldry M, Ibberson M, Hosokawa M \& Thorens B 2002 GLUT2 is a high affinity glucosamine transporter. FEBS Letters 524 199-203.

Vallet JL 1995 Uteroferrin induces lipid peroxidation in endometrial and conceptus microsomal membranes and is inhibited by apotransferrin, retinol binding protein, and the uteroferrin-associated proteins. Biology of Reproduction 53 1436-1445.

Vallet JL 2000 Fetal erythropoiesis and other factors which influence uterine capacity in swine. Journal of Applied Animal Research 17 1-26.

Vallet JL \& Christenson RK 2004 Effect of progesterone, mifepristone, and estrogen treatment during early pregnancy on conceptus development and uterine capacity in swine. Biology of Reproduction $\mathbf{7 0}$ 92-98.

Vallet JL, Christenson RK \& Klemcke HG 1998b Purification and characterization of intrauterine folatebinding proteins from swine. Biology of Reproduction 59 176-181.

Vallet JL, Christenson RK \& McGuire WJ 1996 Association between uteroferrin, retinol-binding protein, and transferrin within the uterine and conceptus compartments during pregnancy in swine. Biology of Reproduction 55 1172-1178.

Vallet JL, Christenson RK, Trout WE \& Klemcke HG 1998a Conceptus, progesterone, and breed effects on uterine protein secretion in swine. Journal of Animal Science 76 2657-2670.

Vallet JL \& Freking BA 2006 Comparison of placental microscopic fold development between large and small fetuses throughout gestation in swine. Biology of Reproduction (Supplement) 163. (Abstract \# 409)

Vallet JL \& Freking BA 2007 Differences in placental structure during gestation associated with large and small pig fetuses. Journal of Animal Science $\mathbf{8 5}$ 3267-3275.

Vallet JL, Miles JR, Brown-Brandl TM \& Nienaber JA 2009 Effect of empty uterine space on placental development, farrowing intervals, and stillbirth. $8 \mathrm{th}$ International Conference on Pig Reproduction, Banff, Canada, 1-4 June 2009. Program \& Abstract 8ook, pp 158, abstr 252-31.

Vallet J, Miles J \& Freking B 2008 Placental hyaluronidase 
expression during gestation in swine. Biology of Reproduction 79(Supplement 1) 235 (Abstract).

Vallet JL, Smith TPL, Sonstegard T, Pearson PL, Christenson RK \& Klemcke HG 1999 Isolation of complementary deoxyribonucleic acids encoding putative secreted and membrane-bound folate binding proteins from endometrium of swine. Biology of Reproduction 61 372-379.

Vogel V \& Sheetz M 2006 Local force and geometry sensing regulate cell functions. Nature Reviews. Molecular Cell Biology 7 265-275.

Vonnahme KA \& Ford SP 2004 Differential expression of the vascular endothelial growth factor-receptor system in the gravid uterus of Yorkshire and Meishan pigs. Biology of Reproduction 71 163-169.

Vonnahme KA, Wilson ME \& Ford SP 2000 The effect of alternating fetal crushing on the growth of remaining conceptuses in Yorkshire $(\mathrm{Y})$ and Meishan $(\mathrm{M})$ pigs. lournal of Animal Science $\mathbf{7 8}$ (Supplement 2) 75 (Abstract).

Vonnahme KA, Wilson ME, Foxcroft GR \& Ford SP 2002 Impacts on conceptus survival in a commercial swine herd. Journal of Animal Science 80 553-559.

Weber RE, Kleinschmidt T \& Braunitzer G 1987 Embryonic pig hemoglobins Gower $\mid\left(\zeta_{2} \varepsilon_{2}\right)$, Gower II $\left(\alpha_{2} \varepsilon_{2}\right)$, Heide I $\left(\zeta_{2} \theta_{2}\right)$ and Heide II $\left(\alpha_{2} \theta_{2}\right)$ : Oxygenbinding functions related to structure and embryonic oxygen supply. Respiration Physiology 69 347-357.

Wen HY, Abbasi S, Kellems RE \& Xia Y 2005 mTOR: A placental growth signaling sensor. Placenta 26 (Supplement A) S63-S69.

West DC, Hampson IN, Arnold F \& Kumar S 1985 Angiogenesis induced by degradation products of hyaluronic acid. Science 228 1324-1326.

White CE, Piper EL \& Noland PR 1979 Conversion of glucose to fructose in the fetal pig. Journal of Animal Science 48 585-590.

Wilson ME, Biensen NJ, Youngs CR \& Ford SP 1998 Development of Meishan and Yorkshire littermate conceptuses in either a Meishan or Yorkshire uterine environment to day 90 of gestation and to term. Biology of Reproduction 58 905-910.
Wilson ME \& Ford SP 1999 The effect of exogenous estradiol-17 $\beta$ ( $E 2 \beta$ ) during elongation on placental size at $\mathrm{d} 112$ of gestation in the Meishan $(M)$ pig. Journal of Animal Science 77(Supplement 1) 71 (Abstract).

Winther $H$, Ahmed A \& Dantzer V 1999 Immunohistochemical localization of vascular endothelial growth factor (VEGF) and its two specific receptors, Flt-1 and KDR, in the porcine placenta and non-pregnant uterus. Placenta 20 35-43.

Wu G, Bazer FW, Hu J, Johnson GA \& Spencer TE 2005 Polyamine synthesis from proline in the developing porcine placenta. Biology of Reproduction 72 842-850.

Wu G, Bazer FW \& Tou W 1995 Developmental changes of free amino acid concentrations in fetal fluids of pigs. The Journal of Nutrition 125 2859-2868.

Wu G, Pond WG, Flynn SP, Ott TL \& Bazer FW 1998 Maternal dietary protein deficiency decreases nitric oxide synthase and ornithine decarboxylase activities in placenta and endometrium of pigs during early gestation. The Journal of Nutrition 128 2395-2402.

Wu G, Bazer FW, Tuo W \& Flynn SP 1996 Unusual abundance of arginine and ornithine in porcine allantoic fluid. Biology of Reproduction 54 1261-1265.

Wu G, Knabe DA \& Kim SW 2004 Arginine nutrition in neonatal pigs. The lournal of Nutrition 134 27835-2790S.

Xie S, Broermann DM, Nephew KP, Bishop MD \& Pope WF 1990 Relationship between oocyte maturation and fertilization on zygotic diversity in swine. Journal of Animal Science 68 2027-2033.

Youdim KA, Martin A \& Joseph JA 2000 Essential falty acids and the brain: possible health implications. International Journal of Developmental Neuroscience 18 383-399.

Zhang Y, Kobayashi K, Kitazawa K, Imai K \& Kobayashi M 2006 Contribution of cooperativity and the Bohr effect to efficient oxygen transport by hemoglobins from five mammalian species. Zoological Science 23 49-55.

Zhao F-Q \& Keating AF 2007 Functional properties and genomics of glucose transporters. Current Cenomics $8113-128$. 